\title{
Penerapan Synthetic Minority Oversampling Technique (SMOTE) Terhadap Data Tidak Seimbang Pada Tingkat Pendapatan Pekerja Informal Di Provinsi D.I. Yogyakarta Tahun 2019
}

\author{
Sabiq Sofyan ${ }^{1 *}$, Achmad Prasetyo ${ }^{2}$ \\ ${ }_{1,2}$ Politeknik Statistika STIS

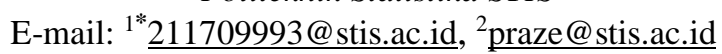

(Application of Synthetic Minority Oversampling Technique (SMOTE) to Unbalanced Data on Income Levels of Informal Workers in the Province of D.I. Yogyakarta Year 2019)

\begin{abstract}
ABSTRAK
Ketenagakerjaan merupakan salah satu permasalahan setiap negara berkembang termasuk di Indonesia. Penciptaan lapangan kerja menjadi isu yang sangat penting terhadap pembangunan ekonomi. Provinsi Daerah Istimewa Yogyakarta merupakan provinsi yang cukup sukses untuk mengatasi masalah ketenagakerjaan dengan TPAK tertinggi ketiga setelah Bali dan Papua tahun 2018 dengan persentase TPAK yang cenderung stabil sejak 2015. Namun, ternyata persentase penduduk miskin yang bekerja di sektor informal di Yogyakarta sangat besar mencapai 44.97\%, hampir mencapai setengah dari seluruhnya. Tingkat pendapatan pekerja di sektor informal jauh lebih rendah daripada pekerja di sektor formal. Data tingkat pendapatan pekerja infomal teridentifikasi sebagai data tidak seimbang karena perbandingan antara pekerja dengan pendapatan rendah dan tinggi sangatlah timpang. Oleh karena itu digunakan metode SMOTE untuk mengatasi masalah data tidak seimbang tersebut. Metode klasifikasi yang digunakan dalam penelitian ini adalah regresi logistik biner. Penelitian ini bertujuan untuk mengetahui variabel yang memengaruhi tingkat pendapatan pekerja informal dan membandingkan model sebelum dan sesudah SMOTE untuk mendapatkan model klasifikasi terbaik. Hasil dari evaluasi model menunjukkan bahwa model setelah SMOTE lebih baik dalam mengklasifikasi tingkat pendapatan pekerja informal. Selanjutnya variabel yang memengaruhi tingkat pemdapatan pekerja informal adalah wilayah tempat tinggal, jenis kelamin, status perkawinan, pelatihan kerja, tingkat pendidikan, lapangan usaha, umur, dan jam kerja.
\end{abstract}

Kata kunci: pendapatan, informal, resampling, SMOTE

\section{ABSTRACT}

Employment is one of the problems of every developing country, including Indonesia. Job creation is a very important issue for economic development. The Province of the Special Region of Yogyakarta is a province that is quite successful in overcoming labor problems with the third highest TPAK after Bali and Papua in 2018 with a percentage of TPAK that has tended to be stable since 2015. However, it turns out that the percentage of poor people who work in the informal sector in Yogyakarta is very large, reaching 44.97\%., almost half of the total. The income level of workers in the informal sector is much lower than that of workers in the formal sector. Data on the income level of informal workers was identified as unbalanced data because the comparison between workers with low and non-low incomes was very unequal. Therefore, the SMOTE method is used to overcome the problem of unbalanced data. The classification method used in this study is binary logistic regression. This study aims to determine the variables that affect the income level of informal workers and compare the models before and after SMOTE to get the best classification model. The results of the model evaluation show that the model after SMOTE is better at classifying the income level of informal workers. Furthermore, the variables that affect the income level of informal workers are classification of residence, gender, marital status, job training, education level, business field, age, and working hours.

Keywords: income, informal, resampling, SMOTE

\section{PENDAHULUAN}

Data dengan komposisi rasio yang tidak seimbang antara satu kategori dengan kategori lainnya dapat dinyatakan sebagai data yang imbalanced. Data imbalanced dapat diartikan sebagai data dengan jumlah objek data pada kelas mayoritas jauh lebih banyak dibandingkan dengan jumlah objek data pada kelas minoritas (Untoro, 2018). Penggunaan data yang imbalanced untuk membangun sebuah model akan sangat mempengaruhi hasil pembetukan model yang didapatkan. Pengolahan algoritma klasifkasi yang mengabaikan ketidakseimbangan data akan cenderung lebih memperhatikan kelas mayor dan mengabaikan kelas minor (Chawla, et al. 2002). Dalam hal ini data imbalanced tidak terlalu dipermasalahkan ketika perbandingan antar kelasnya tidak berbeda jauh. Data imbalanced akan menjadi masalah ketika perbandingan antar kelas mayoritas dan minoritas sangat besar, sehingga dapat memengaruhi hasil evaluasi. Jika penggunaan data 
imbalanced tetap dipaksakan pada pengolahan data, hampir semua algoritma klasifikasi akan menghasilkan akurasi yang jauh lebih tinggi untuk kelas mayoritas daripada kelas minoritas. Informasi yang lebih banyak dari kelas mayoritas mendominasi dan menutup informasi dari kelas minoritas sehingga mengakibatkan batas-batas keputusan yang bias dalam sistem klasifikasi (Jian,et al. 2016).

Dalam mengatasi masalah data imbalanced salah satu alternatif yang dapat digunakan adalah menggunakan Metode Synthetic Minority Oversampling Technique (SMOTE). Metode SMOTE ini merupakan metode yang cukup populer untuk mengatasi masalah data imbalanced. Metode SMOTE ini adalah pengembangan dari metode oversampling, dimana cara kerja metode ini adalah dengan membangkitkan sampel baru yang berasal dari kelas minoritas untuk membuat proporsi data menjadi lebih seimbang dengan cara sampling ulang sampel kelas minoritas (Siringoringo, 2018). Dengan pendekatan metode SMOTE tersebut penelitian ini akan mengkaji tentang tingkat pendapatan pekerja informal di Provinsi Daerah Yogyakarta tahun 2019.

Penduduk yang terus bertambah pasti akan membutuhkan lapangan kerja sebagai sumber penghasilan untuk memenuhi kebutuhan sehari-hari. Penciptaan lapangan kerja menjadi isu yang sangat penting terhadap pembangunan ekonomi. Meskipun sudah terdapat banyak sektor pekerjaan yang tersedia, namun sampai saat ni hal tersebut dinila kurang mampu menyerap angkatan kerja yang terus meningkat sebagai dampak dari adanya ketimpangan antara pertumbuhan angkatan kerja yang tumbuh dengan cepat dan lapangan kerja yang tersedia. BPS (2019) mencatat bahwa situasi ketenagakerjaan di Indonesia saat ini menggambarkan bahwa sebagian besar dari angkatan kerja bekerja pada lapangan kerja informal dengan keterampilan rendah dan tingkat pendidikan yang rendah, lebih detailnya ada sebanyak 74,08 juta orang $(57,27$ persen $)$ bekerja pada kegiatan informal dan sebanyak 55,28 juta orang (42,73 persen) penduduk bekerja pada kegiatan formal.

Berbicara mengenai masalah ketenagakerjaan di Indonesia, Daerah Istimewa Yogyakarta merupakan provinsi yang cukup sukses untuk mengatasi masalah ketenagakerjaan. Pada tahun 2018, Daerah Istimewa Yogyakarta merupakan provinsi dengan TPAK (Tingkat Partisipasi Angkatan Kerja) tertinggi ketiga setelah Bali dan Papua. Namun, ternyata dalam publikasi Statistik Kemiskinan Provinsi Daerah Istimewa Yogyakarta tahun 2019 menunjukkan bahwa persentase penduduk miskin yang bekerja di sektor informal di Yogyakarta sangat besar mencapai $44.97 \%$, hampir mencapai setengah dari seluruhnya. Apabila ditinjau dari segi pendapatan, maka pekerja di sektor informal jauh lebih rendah daripada pekerja di sektor formal. Persentase pekerja informal yang memiliki pendapatan dibawah Upah Minimum Provinsi (UMP) Yogyakarta sebesar 85,89\% sedangkan untuk pekerja informal dengan pendapatan diatas UMP Yogyakarta hanya sebesar 14,11\%. Jumlah pekerja informal dengan pendapatan dibawah UMP Yogyakarta jauh lebih banyak dibanding pekerja informal dengan pendapatan diatas UMP Yogyakarta. Sampa saat ini belum ada pernyataan secara pasti tentang berapa rasio pasti sebuah data sehingga data dapat dikatakan sebagai imbalanced. beberapa kasus penerapan klasifkasi, data dengan rasio sekitar $1: 10$ pada kategorinya akan mengurangi keakuratan kinerja klasifikasi karena ukuran sampel yang tidak seimbang atau imbalanced (Yanmisun, et al 2011). Data yang imbalanced akan memerlukan penanganan ketika klasifikasi yang dihasilkan tidak seimbang dan mempengaruhi evaluasi pada klasifkasi. Dalam hal ini data pendapatan pekerja informal di Provinsi Yogyakarta mengindikasikan bahwa adanya imbalanced karena perbedaan persentase yang cukup jauh antar kategorinya dan ada kemungkinan akan mempengaruhi hasil evaluasi pada klasifikasi yang dilakukan, oleh karena itu penelitian ini bertujuan untuk melakukan kajian mengenai keseimbangan klasifikasi pada data pekerja informal di Provinsi Yogyakarta dan mengatasi masalah imbalanced data dengan melakukan penerapan metode SMOTE.

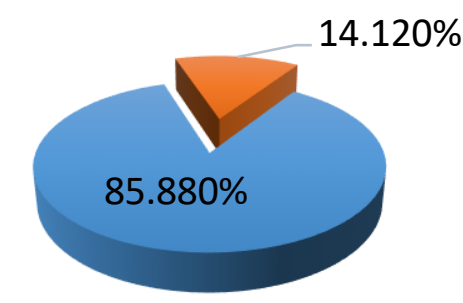

- Pendapatan Rendah $\quad$ Pendapatan Tinggi

Sumber: SAKERNAS Agustus 2019

Gambar 1. Persentase tingkat pendapatan pekerja informal di Provinsi D.I. Yogyakarta tahun 2019 


\section{METODE}

\section{Synthetic Minority Oversampling Technique (SMOTE)}

Metode SMOTE diperkenalkan oleh Nithes V. Chawla pada tahun 2002 dalam rangka memberi salah satu solusi dalam mengatasi permasalahan data tidak seimbang dengan dasar pengolahan yang berbeda dari metode oversampling yang telah diperkenalkan sebelumnya. Pada metode oversampling, pada dasarnya prinsip yang digunakan adalah memperbanyak pengamatan secara acak. Pada metode SMOTE ini, prinsip yang digunakan adalah menambah jumlah data kelas minor agar setara dengan kelas mayor dengan cara membangkitkan synthesis data atau data buatan. Data buatan tersebut dibangkitkan berdasarkan atribut yang berasal dari $k$ nearest neighbor. Untuk jumlah $k$-nearest neighbor, dapat ditentukan sesuai dengan pertimbangan kemudahan untuk menjalankannya. Untuk pembuatan sintesis data buatan berskala numerik tidak sama dengan data buatan yang berskala kategorik. Pada data numerik, jarak kedekatan dengan tetangganya diukur dengan jarak Euclidean sedangkan data kategorik dengan nilai Value Difference Metric (VDM). (Chawla,et al 2002). Tahapan metode yang dilakukan adalah:

1. Membagi data menjadi dua yaitu testing dan training dengan perbandingan $20: 80$ secara acak.

2. Melakukan SMOTE pada tahap praproses data dengan target data kelas minoritas

3. Membangun model regresi logistik biner dengan data sesudah dilakukan proses SMOTE.

4. Melakukan evaluasi dan membandingkan evaluasi model sebelum dan sesudah dilakukan SMOTE dari tabel kesesuaian klasifikasi dan nilai AUC masing-masing model.

5. Memilih model terbaik dan melakukan regresi logistik biner pada model.

\section{Regresi Logistik Biner}

Regresi logistik biner adalah suatu metode analisis data yang penerapannya ditujukan untuk menemukan hubungan antara variabel respon yang bersifat dikotomus atau biner dengan variabel prediktor yang bersifat polikotomus (Bentuk umum model logistik dengan p variabel bebas menurut Hosmer dan Lemeshow (2000) adalah :

$\boldsymbol{\pi}(\mathbf{x})=\frac{\left(\exp \left(\beta_{0}+\beta_{1} x_{1}+\beta_{2} x_{2}+\cdots+\beta_{p} x_{p}\right)\right)}{\left(1+\exp \left(\beta_{0}+\beta_{1} x_{1}+\beta_{2} x_{2}+\cdots+\beta_{p} x_{p}\right)\right)}$

Keterangan:

$\boldsymbol{\pi}(\mathbf{x})$ : Peluang $\mathrm{Y}=1$ atau peluang terjadinya kejadian sukses

$\boldsymbol{\beta}_{\boldsymbol{j}}$ : Nilai parameter ke-j dengan $j=0,1,2, \ldots, \boldsymbol{p}$

$\boldsymbol{p}$ : Jumlah variabel bebas

\section{Data dan Variabel Penelitian}

Penelitian ini mencakup Provinsi Daerah Istimewa Yogyakarta pada tahun 2019. Unit analisis dalam penelitian ini adalah pekerja sektor informal di Provinsi Daerah Istimewa Yogyakarta tahun 2019. Variabel dependen yang digunakan dalam penelitian ini yaitu pendapatan tenaga kerja sektor informal yang dikategorikan menjadi pendapatan rendah dan pendapatan tinggi. Pendapatan dikategorikan sebagai pendapatan yang rendah apabila nilainya berada dibawah nilai Upah Minimum Provinsi Daerah Istimewa Yogyakarta tahun 2019 yaitu sebesar Rp. 1.520.922 . Pendapatan dikategorikan tinggi apabila nilainya lebih besar dari Upah Pendapatan Minimum Provinsi Daerah Istimewa Yogyakarta tahun 2019. Sementara itu variabel penjelas dalam penelitian ini dipilih berdasarkan kajian teori yang telah didapat dan penelitian terdahulu yang telah dikaji. Variabel penjelas terdiri dari wilayah tempat tinggal (Pasay \& Indrayanti, 2012), jenis kelamin (Arfida, 2003), status perkawinan (Pasay \& Indrayanti, 2012), pelatihan kerja (Arfida, 2003), tingkat pendidikan (Faridi et al., 2013), lapangan usaha, umur (Faridi et al., 2013), dan jam kerja (Faridi et al., 2013). Data mengenai variabel-variabel yang digunakan diambil melalui data sekunder dari SAKERNAS Agustus 2019.

\section{HASIL DAN PEMBAHASAN}

\section{Regresi Logistik Biner Sebelum SMOTE}

Sesuai dengan tahapan analisis mata metode penelitan maka analisis regresi logistik biner dilakukan untuk mengetahui variabel-variabel yang berpengaruh terhadap tingkat pendapatan pekerja informal di Provinsi Daerah Istimewa Yogyakarta. Pendugaan dan pengujian parameter terlebih dahulu dilakukan tanpa proses 
SMOTE dan mengabaikan imabalanced data. Hasil pendugaan parameter untuk membentuk model regresi logistik biner dalam penelitian ini dapat dilihat pada tabel 1.

Tabel 1. Hasil pendugaan parameter dan signifikasi variabel model sebelum SMOTE

\begin{tabular}{lccc}
\hline \multicolumn{1}{c}{ Variabel } & $\hat{\beta}$ & Wald & $p$-value \\
\hline Konstanta & $-3,1894$ & -10.291 & 0.000 \\
Wilayah tempat tinggal $\left(\mathrm{X}_{1}\right)$ & $-0,3939$ & -2.857 & 0.004 \\
Jenis Kelamin $\left(\mathrm{X}_{2}\right)$ & -1.6314 & -11.838 & 0.000 \\
Status Perkawinan $\left(\mathrm{X}_{3}\right)$ & 0.4089 & 2.296 & 0.021 \\
Pelatihan Kerja $\left(\mathrm{X}_{4}\right)$ & 0.2864 & 1,673 & 0.094 \\
Tingkat Pendidikan $\left(\mathrm{X}_{5}\right)$ & & & \\
$\quad$ & 0.4206 & 2.963 & 0.003 \\
$\quad$ Pendidikan menengah $\left(X_{51}\right)$ & 1.0870 & 4,684 & 0.000 \\
$\quad$ Pendidikan tinggi $\left(X_{52}\right)$ & & & \\
Lapangan Usaha $\left(\mathrm{X}_{6}\right)$ & 1.2869 & 6,690 & 0.000 \\
$\quad$ Sektor sekunder $\left(X_{61}\right)$ & 1.1885 & 6.416 & 0.000 \\
$\quad$ Sektor tersier $\left(X_{62}\right)$ & -0.7102 & -3.906 & 0.000 \\
Umur $\left(\mathrm{X}_{7}\right)$ & 0.8729 & 7.185 & 0.000 \\
Jam Kerja $\left(\mathrm{X}_{8}\right)$ & & & \\
\hline
\end{tabular}

Selanjutnya dilakukan pengujian parameter secara simultan dan diperoleh nilai uji statistik $\mathrm{G}$ yang dihasilkan sebesar 486 dengan nilai $\chi_{(0,05,17)}^{2}=27,5871$. Karena nilai $\mathrm{G}$ lebih besar dari nilai $\chi_{(0,05,17)}^{2}$ maka diambil keputusan tolak $\mathrm{H}_{0}$ yang berarti terdapat minimal satu variabel prediktor yang memiliki pengaruh yang signifikan terhadap variabel respon. Setelah melakukan uji simultan maka selanjutnya dilakukan pengujian signifikansi secara parsial pada parameter dalam model. Hasil diperoleh variabel yang signifikan berpengaruh terhadap pendapatan pekerja informal di Provinsi Daerah Istimewa Yogyakarta yaitu variabel Wilayah tempat tinggal (X1), Jenis Kelamin (X2), Status Perkawinan (X3), Tngkat pendidikan (X5), Lapangan Usaha (X6), Umur(X7), dan jam kerja (X8). Untuk tabel klasifikasi model dapat dilihat pada tabel 2.

Berdasarkan hasil pendugaan parameter tersebut diperoleh persamaan logit pada regresi logistik biner sebagai berikut:

$$
\begin{gathered}
g(x)=-3,1894-0,3939 X_{1}-1.6314 X_{2}+0.4089 X_{3}+0.2864 X_{4}+0.4206 X_{51}+1.0870 X_{52} \\
+1.2869 X_{61}+1.1885 X_{62}-0.7102 X_{7}+0.8729 X_{8}
\end{gathered}
$$

Tabel 2. Tabel klasifkasi model

\begin{tabular}{cccc}
\hline \multirow{2}{*}{ Observasi } & \multicolumn{2}{c}{ Prediksi } & \multirow{2}{*}{ Percentage Correct } \\
\cline { 2 - 3 } & Pendapatan rendah & Pendapatan tinggi & 98,26 \\
Pendapatan rendah & 620 & 96 & 11,91 \\
Pendapatan tinggi & 11 & 13 & 85,54 \\
Overall Percentage & & & \\
\hline
\end{tabular}

Hasil klasifikasi menghasilkan nilai akurasi sebesar 85,78 persen, nilai sensitivitas sebesar 98,26 persen dan nilai spesifisitasnya sebesar 11,91 persen. Nilai spesifisitas yang sangat kecil pada tabel klasifikasi tersebut menunjukkan bahwa model tidak dapat mengklasifikasikan kategori pekerja informal dengan pendapatan tinggi dengan benar. Hal ini menunjukkan bahwa klasifikasi cenderung memprediksi kategori mayor dan mengabaikan kategori minor sehingga terdapat kesalahan ketepatan klasifisikasi pada kategori minor hal tersebut yang menyebabkan data imbalanced dan membuat klasifikasi menjadi kurang tepat. Oleh karena itu dapat dikatakan model regresi logistk biner yang mengandung data imbalanced ini belum mampu mengklasifikasikan pekerja informal dengan pendapatan tinggi dengan baik, sehingga memerlukan penanganan terhadap kategori data yang tidak seimbang agar hasilnya menjadi lebih baik. Dalam hal ini akan dilakukan SMOTE untuk menangani data yang imbalanced tersebut.

\section{Penerapan SMOTE pada Model Regresi Logistik Biner}

Tahapan awal SMOTE adalah melakukan langkah pembangkitan data buatan. Persentase awal jumlah amatan pada kategori minor adalah sebesar $14,34 \%$ sedangkan untuk kategori mayor sebesar 85,66\%. 
Kemudian dilakukan proses SMOTE pada data training dengan beberapa parameter SMOTE yang berbeda pada masing-masing model.

Parameter SMOTE yang pertama adalah oversampling $300 \%$ yang berarti akan dibangkitkan data buatan sebanyak tiga kali jumlah amatan kategori minor awal, sehingga akan ditambahkan 1299 amatan pada data minor. Selanjutnya diperoleh persentase pada kategori mayor sebesar $60,65 \%$ dan persentase pada kategori minor sebesar 39,35\%. Parameter SMOTE yang kedua adalah oversampling 400\% yang berarti akan dibangkitkan data buatan sebanyak empat kali jumlah amatan kategori minor awal, sehingga akan ditambahkan 1732 amatan pada data minor. Selanjutnya diperoleh persentase pada kategori mayor sebesar 55,22\% dan persentase pada kategori minor sebesar 44,78\%. Parameter SMOTE yang ketiga adalah oversampling 500\% yang berarti akan dibangkitkan data buatan sebanyak lima kali jumlah amatan kategori minor awal. Sehingga akan ditambahkan 2165 amatan pada data minor. Selanjutnya setelah tahapan ini diperoleh persentase pada kategori mayor sebesar 50,68\% dan persentase pada kategori minor sebesar 49,32\%.

Ketiga data yang telah melalui tahapan SMOTE dari tiga parameter SMOTE tersebut menghasilkan persentase antara dua kategori menjadi lebih seimbang jika dibandingkan dengan persentase antara dua kategori sebelum dilakukan SMOTE. Ketiga data yang telah melalui tahapan SMOTE selanjutnya digunakan untuk membangun model menggunakan regresi logistik biner. Hasil pengujian parameter regresi logistik biner secara simultan pada ketiga model yang telah dilakukan SMOTE dirangkum pada tabel 3.

Tabel 3. Hasil uji simultan pada model setelah dilakukan SMOTE

\begin{tabular}{cc}
\hline Parameter SMOTE & Nilai G \\
\hline Oversampling 300\% & 1446,7 \\
Oversampling 400\% & 1629,8 \\
Oversampling 500\% & 1840,3 \\
\hline
\end{tabular}

Dari tabel 3 tersebut dapat dilihat bahwa pengujian parameter secara simultan pada ketiga model dari data yang telah dilakukan SMOTE semuanya mendapatkan nilai $G$ yang lebih besar dari $\chi_{(0,05,17)}^{2}=27,5871$. Karena nilai $\mathrm{G}$ yang lebih besar dari $\chi_{(0,05,17)}^{2}$ maka diambil keputusan tolak $\mathrm{H}_{0}$ yang berarti terdapat minimal satu variabel penjelas yang memiliki konstribusi yang signifikan terhadap variabel respon. Dari hasil tersebut menunjukkan bahwa ketiga model setelah dilakukan SMOTE dapat dianalisis lebih lanjut dengan regresi logistk biner.

\section{Evaluasi Model Setelah SMOTE}

Evaluasi model yang digunakan adalah nilai ketepatan klasifikasi berdasarkan tabel ketepatan klasifikasi dan nilai AUC. Nilai ketepatan klasifikasi dan nilai AUC dari ketiga model yang setelah SMOTE dibandingkan pada model sebelum SMOTE dapat dilihat pada Tabel 4.

Tabel 4. Hasil evaluasi model

\begin{tabular}{ccccc}
\hline \multirow{2}{*}{ Ukuran Klasfikasi } & Sebelum SMOTE & \multicolumn{3}{c}{ Parameter SMOTE } \\
\cline { 3 - 5 } & & Oversampling 300\% & Oversampling 400\% & \multirow{2}{*}{ Oversampling 500\% } \\
\hline Spesifisitas & $11,91 \%$ & $56,72 \%$ & $70,64 \%$ & $74,31 \%$ \\
Sensitivitas & $98,26 \%$ & $80,51 \%$ & $75,28 \%$ & $73,69 \%$ \\
Akurasi & $85,54 \%$ & $77,30 \%$ & $74,59 \%$ & $73,78 \%$ \\
G-means & 0,342 & 0,673 & 0,723 & 0,739 \\
AUC & 0,7841 & 0,7842 & 0,7874 & 0,7876 \\
\hline
\end{tabular}

Tabel 4 menunjukkan bahwa bahwa model sebelum SMOTE menghasilkan nilai akurasi sebesar 85,74\%, nilai sensitivitas sebesar $98,74 \%$, nilai spesifisitasnya sebesar $11,91 \%$, nilai G-means sebesar 0,342 , dan nilai AUC sebesar 0,7841. Akan tetapi, nilai spesifitas sangat rendah. Hal ini menunjukkan bahwa klasifikasi cenderung memprediksi kategori mayor dan mengabaikan kategori minor sehingga terjadi terdapat kesalahan ketepatan klasifisikasi pada kategori minor. Ketiga model setelah dilakukan SMOTE sudah mampu untuk mengklasifikasikan kategori minor yaitu pekerja informal dengan pendapatan tinggi dengan baik sesuai tujuan dari penelitian. Hal tersebut dinilai dari proporsi data pada kelas mayor dan kelas minor yang sudah seimbang, selain itu nilai sensitivitas dari data awal sudah meningkat yang sebelumnya sangat kecil hingga menjadi cukup baik diatas $50 \%$. 
Pemilihan model terbaik untuk digunakan pada penelitian ini dilakukan dengan mempertimbangkan keseluruhan nilai evaluasi model. Berdasarkan pertimbangan tersebut, model yang dipilih adalah model dengan parameter SMOTE Oversampling 500\%. Pada model dengan dengan parameter SMOTE Oversampling 500\% menunjukkan evaluasi model yang bagus secara keseluruhan. Jika dilihat dari tujuan penelitian agar model dapat mencakup semua kategori dengan benar dan tidak cenderung memprediksi kategori mayor yaitu dengan melihat nilai $G$-means yang lebih tinggi, maka nilai $G$-means pada model tersebut merupakan yang terbesar diantara model yang lain. Model tersebut juga memiliki nilai AUC lebih baik daripada model sebelum SMOTE artinya tingkat akurasi klasifikasi model pada model tersebut lebih baik. Untuk selanjutnya model ini yang akan dipilih dan digunakan dalam penelitian ini.

\section{Model Regresi Logistik Biner Setelah SMOTE}

Dari model terbaik yang sudah dipilih, selanjutnya dilakukan pengolahan data dengan regresi logistik biner. Setelah melakukan pengolahan data dengan memasukkan seluruh variabel maka diperoleh nilai estimasi untuk parameter regresi logistik biner sebagai berikut :

Tabel 5. Hasil pendugaan parameter model terbaik setelah dilakukan SMOTE

\begin{tabular}{|c|c|c|c|c|}
\hline Variabel & $\hat{\beta}$ & $\overline{\exp (\widehat{\beta})}$ & Wald & $p$-value \\
\hline Konstanta & -1.4952 & 0.2242 & -8.585 & 0.000 \\
\hline Wilayah tempat tinggal $\left(\mathrm{X}_{1}\right)$ & -0.5431 & 0.5809 & -6.979 & 0.000 \\
\hline Jenis Kelamin $\left(\mathrm{X}_{2}\right)$ & -1.7534 & 0.1731 & -22.919 & 0.000 \\
\hline Status Perkawinan $\left(\mathrm{X}_{3}\right)$ & 0.6263 & 1.8701 & 5.740 & 0.000 \\
\hline Pelatihan Kerja $\left(\mathrm{X}_{4}\right)$ & 0.2843 & 1.3289 & 2.759 & 0.005 \\
\hline \multicolumn{5}{|l|}{ Tingkat Pendidikan $\left(\mathrm{X}_{5}\right)$} \\
\hline Pendidikan menengah $\left(X_{51}\right)$ & 0.3972 & 1.4877 & 4.902 & 0.000 \\
\hline Pendidikan tinggi $\left(X_{52}\right)$ & 0.9511 & 2.5885 & 6.565 & 0.000 \\
\hline \multicolumn{5}{|l|}{ Lapangan Usaha $\left(\mathrm{X}_{6}\right)$} \\
\hline Sektor sekunder $\left(X_{61}\right)$ & 1.1618 & 3.1958 & 11.374 & 0.000 \\
\hline Sektor tersier $\left(X_{62}\right)$ & 1.2456 & 3.4759 & 12.721 & 0.000 \\
\hline $\operatorname{Umur}\left(\mathrm{X}_{7}\right)$ & -0.9740 & 0.3775 & -9.669 & 0.000 \\
\hline $\operatorname{Jam} \operatorname{Kerja}\left(\mathrm{X}_{8}\right)$ & 0.9597 & 2.6109 & 13.568 & 0.000 \\
\hline
\end{tabular}

Pengujian parameter secara simultan yang telah dilakukan pada tabel 5 diperoleh nilai uji statistik $\mathrm{G}$ yang dihasilkan sebesar 1019,71. Karena nilai G lebih besar dari nilai $\chi_{(0,05,17)}^{2}=27,5871$ maka diambil keputusan tolak $\mathrm{H}_{0}$ yang berarti terdapat minimal satu variabel prediktor yang memiliki konstribusi yang signifikan terhadap variabel respon. Setelah melakukan uji simultan maka selanjutnya dilakukan pengujian signifikansi secara parsial pada parameter dalam model. Hasil diperoleh variabel yang signifikan berpengaruh terhadap pendapatan pekerja informal di Provinsi Daerah Istimewa Yogyakarta yaitu variabel Jenis Kelamin (X2), Pelatihan Kerja (X4), Tingkat pendidikan (X5), Lapangan Usaha (X6), Umur(X7), Lama Usaha (X8), dan jam kerja (X9).

Adapun model persamaan logit pada regresi logistik biner yang diperoleh berdasarkan variabel yang signigikan sebagai berikut:

$$
\begin{gathered}
\hat{g}(x)=-1.4952-0.5431 X_{1}-1.7534 X_{2}+0.6263 X_{3}+0.2843 X_{4}+0.3972 X_{51}+0.9511 X_{52} \\
+1.1618 X_{61}+1.2456 X_{62}-0.9740 X_{7}+0.9597 X_{8}
\end{gathered}
$$

\section{Kecenderungan Variabel yang Mempengaruhi Tingkat Pendapatan Pekerja Sektor Informal}

Dari persamaan regresi logistik biner yang terbentuk dapat diketahui nilai odds ratio pada masing-masing variabel penjelas yang signifkan mempengaruhi tingkat pendapatan pekerja informal di Provinsi Daerah Istimewa Yogyakarta. Odds ratio digunakan untuk melihat kecenderungan tingkat pendapatan pekerja informal di Provinsi Daerah Istimewa Yogyakarta. Adapun interpretasi odds ratio pendapatan pekerja informal di Provinsi Daerah Istimewa Yogyakarta adalah sebagai berikut :

\section{Wilayah Tempat Tinggal}

Hasil analisis dengan regresi logistik biner menghaslkan nilai odds ratio untuk variabel wilayah tempat tinggal sebesar 0,5809. Nilai tersebut menunjukkan bahwa seorang pekerja informal yang tinggal di pedesaan memiliki kecenderungan untuk berpendapatan tinggi sebesar 0,5809 kali dibandingkan dengan pekerja 
informal yang tinggal di perkotaan. Dengan kata lain, seorang pekerja informal yang tinggal di perkotaan memiliki kecenderungan untuk berpendapatan tinggi sebesar 1/0,5809 $=1,721$ kali lebih besar dibandingkan dengan pekerja informal yang tinggal di pedesaan. Hal tersebut sejalan dengan temuan Pasay \& Indrayanti (2012) dimana pekerja yang tinggal di daerah perkotaan memiliki kecenderungan partisipasi bekerja lebih tinggi dibandingkan dengan pekerja yang tinggal di daerah pedesaan. Pekerja di daerah perkotaan cenderung memiliki produktivitas dan keterampilan labih tinggi dibanding pekerja di daerah pedesaan. Hal tersebut tentunya berpengaruh terhadap pendapatan yang dihasilkan. Selain itu biaya hidup di perkotaan yang cenderung lebih mahal dari pedesaan juga membuat para pekerja di perkotaan akan menyesuaikan dan mencari pekerjaan dengan pendapatan pendapatan yang lebih agar bisa memenuhi kebutuhan hidupnya.

\section{Jenis Kelamin}

Hasil analisis dengan regresi logistik biner menghaslkan nilai odds ratio untuk variabel jenis kelamin ialah sebesar 0,1731. Nilai tersebut menunjukkan bahwa seorang pekerja informal yang berjenis kelamin perempuan memiliki kecenderungan untuk berpendapatan tinggi sebesar 0,1731 kali dibandingkan dengan pekerja informal yang berjenis kelamin laki-laki. Dengan kata lain, seorang pekerja informal yang berjenis kelamin laki-laki memiliki kecenderungan untuk berpendapatan tinggi sebesar 1/0,1731 $=5,777$ kali lebih besar dibandingkan dengan pekerja informal yang berjenis kelamin perempuan.. Hasil ini sesuai dengan penelitian yang telah dilakukan oleh Bhaskara \& Wardana (2019) menyimpulkan bahwa dalam realita kehidupan sehari-hari, suami yang memiliki kewajiban sebagai tulang punggung keluarga oleh sebab itu kesempatan perempuan untuk memperoleh pendapatan lebih tinggi memilik kemungkinan lebih rendah dibandingkan dengan laki-laki karena kesempatan pekerjaan yang ditawarkan pada keduanya berbeda.

\section{Status Perkawinan}

Hasil analisis dengan regresi logistik biner menghaslkan nilai odds ratio untuk variabel status perkawinan ialah sebesar 1,8701. Nilai tersebut menunjukkan bahwa seorang pekerja informal yang berstatus sudah kawin memiliki kecenderungan untuk berpendapatan tinggi sebesar 1,8701 kali lebih besar dibandingkan dengan pekerja informal yang berstatus belum kawin. Hal ini sejalan dengan penelitian yang telah dilakukan Faridi (2013) yang menjelaskan bahwa pekerja yang telah menikah akan cenderung untuk memperoleh pendapatan yang lebih banyak. Hal tersebut dikarenakan kebutuhan yang harus ditanggung akan lebih banyak setelah menikah sehingga akan menambah pendapatan yang harus diperoleh.

\section{Pelatihan Kerja}

Hasil analisis dengan regresi logistik biner menghaslkan nilai odds ratio untuk variabel pelatihan kerja sebesar 1,3289. Nilai tersebut menunjukkan bahwa seorang pekerja informal yang pernah mengikuti pelatihan kerja memiliki kecenderungan untuk berpendapatan tinggi sebesar 1,3289 kali lebih besar dibandingkan dengan pekerja informal yang tidak pernah mengikuti pelatihan kerja. Pelatohan kerja tentunya akan menambah nilai dan produktivitas Hasil ini sesuai dengan penelitian yang telah dilakukan Faridi (2013) yang menjelaskan bahwa pekerja yang telah mengikuti semacam pelatihan akan mempengaruhi pendapatan yang diperoleh tiap bulannya secara positif dan signifikan. Penelitian Pasay \& Indrayanti (2012) juga menerangkan bahwa pekerja yang pernah mengikut pelatihan kerja akan cendeung memliliki partisipasi bekerja yang lebih baik daripada pekerja yang tidak pernah mengikuti pelatihan kerja.

\section{Tingkat Pendidikan}

Hasil analisis dengan regresi logistik biner menghaslkan nilai odds ratio untuk variabel Tingkat pendidikan menengah sebesar 1,4877 . Nilai tersebut menunjukkan bahwa seorang pekerja informal yang berpendidikan menengah memiliki kecenderungan untuk berpendapatan tinggi sebesar 1,4877 kali lebih besar dibandingkan dengan pekerja informal yang berpendidikan dasar. Sedangkan nilai odds ratio untuk variabel Tingkat pendidikan tinggi sebesar 2,5885. Nilai tersebut menunjukkan bahwa seorang pekerja informal yang berpendidikan tinggi memiliki kecenderungan untuk berpendapatan tinggi sebesar 2,5885 kali lebih besar dibandingkan dengan pekerja informal yang berpendidikan dasar. Hal tersebut menunjukkan bahwa tingkat pendidikan berbanding lurus terhadap pendapatan seseorang. Semakin tinggi pendidikan yang ditamatkan maka akan semakin tinggi pula kemungkinan pendapatan yang akan diperoleh. Becker (1993) menjelaskan bahwa seseorang yang memiliki pendidikan yang tinggi dapat meningkatkan kesejahteraannya karena hal tersebut berbanding lurus dengan keterampilan yang didapat. Sedangkan Sukirno (2005) Berpendapat bahwa tenaga kerja dengan pendidikan lebih tinggi akan memperoleh keterampilan yang bisa meningkatkan 
pendapatan dan produktivitas kerja. Hal ini sesuai dengan penelitian yang telah dilakukan oleh Putri \& Setiawina (2013) yang menjelaskan bahwa tingkat pendidikan akan berpengaruh positif terhadap pendapatan pekerja. Semakin tinggi pendidikan seseorang maka pekerjaan dan pendapatannya akan semakin layak dan meningkat seiring dengan keterampilan yang diperoleh.

\section{Lapangan Usaha}

Hasil analisis dengan regresi logistik biner menghaslkan nilai odds ratio untuk variabel Lapangan Usaha Sektor Sekunder sebesar 3,1958. Nilai tersebut menunjukkan bahwa seorang pekerja informal yang bekerja pada sektor sekunder memiliki kecenderungan untuk berpendapatan tinggi sebesar 3,1958 kali lebih besar dibandingkan dengan pekerja informal yang bekerja pada sektor primer. Sektor sekunder yang terdiri dari lapangan usaha industri pengolahan, listrik, gas dan air, serta bangunan; dinilai lebih produktif dan menghasilkan pendapatan yang lebih besar daripada sektor primer yang terdiri dari lapangan usaha pertanian, peternakan, kehutanan, perikanan, pertambangan dan penggalian. Todaro \& Smith (2003) menjelaskan bahwa menurut teori pembangunan Lewis, tingkat pendapatan pada sektor industri modern jika diasumsikan konstan maka jumlahnya ditetapkan melebihi tingkat rata-rata pendapatan di sektor pertanian tradisional.

Sedangkan nilai odds ratio untuk variabel lapangan usaha sektor tersier sebesar 3,4759. Nilai tersebut menunjukkan bahwa seorang pekerja informal yang bekerja pada sektor terser memiliki kecenderungan untuk berpendapatan tinggi sebesar 3,4759 kali lebih besar dibandingkan dengan pekerja informal yang bekerja pada sektor primer. Sektor tersier yang terdiri dari lapangan usaha perdagangan, hotel, restoran, pengangkutan, komunikasi, keuangan, sewa, dan jasa perusahaan, serta jasa-jasa lain; menghasilkan lebih banyak upah daripada sektor primer yang terdiri dari lapangan usaha pertanian, peternakan, kehutanan, perikanan, pertambangan dan penggalian.

\section{Umur}

Hasil analisis dengan regresi logistik biner menghaslkan nilai odds ratio untuk variabel umur ialah sebesar 0,3775. Nilai tersebut menunjukkan bahwa seorang pekerja informal yang berumur 60 tahun keatas memiliki kecenderungan untuk berpendapatan tinggi sebesar 0,3775 kali dibandingkan dengan pekerja informal yang berumur kurang dari 60 tahun. Dengan kata lain, seorang pekerja informal yang berumur kurang dari 60 tahun memiliki kecenderungan untuk berpendapatan tinggi sebesar 1/0,3775 =2,649 kali lebih besar dibandingkan dengan pekerja informal yang berumur 60 tahun keatas. Seseorang dikategorikan sebagai lanjut usia jika berumur 60 tahun keatas. Pada rentang usia tersebut semakin seseorang bertambah tua maka akan semakin berkurang kekuatan fisiknya dan akan mempengaruhi produktivitas kerjanya sehingga menurunkan pendapatan yang diperoleh. Seperti yang telah dijelaskan Siimanjuntak (2001), Pekerjaan informal lebih bergantung pada tenaga fisik sehingga semakin berumur fisik seseorang maka tenaga untuk bekerja juga akan bertambah, akan tetapi jika sudah memasuki usia 60 tahun ke atas maka tenaga fisik akan menurun dan berpengaruh terhadap produktivitas. Berbeda dengan sektor formal yang semakin tua maka pengalaman dan relasi yang diperoleh semakin banyak sehingga pendapatan meningkat, sektor nformal yang kebanyakan lebih mengandalkan fisik akan semakin menurun pendapatannya jika semaikin tua.

\section{Jam Kerja}

Hasil analisis dengan regresi logistik biner menghaslkan nilai odds ratio untuk variabel status perkawinan ialah sebesar 2,6109. Nilai tersebut menunjukkan bahwa seorang pekerja informal yang bekerja 40 jam atau lebih dalam seminggu memiliki kecenderungan untuk berpendapatan tinggi sebesar 2,6109 kali dibandingkan dengan pekerja informal yang bekerja kurang dari 40 jam dalam seminggu. Hasil ini sejalan dengan penelitian yang. Hal tersebut menunujukan bahwa semakin lama jam kerja selama seminggu terkahir maka semakin tinggi pendapatan yang dihasilkan. Pekerja dengan jam kerja yang lebih tinggi akan lebih produktif sehingga bisa menyelesaikan lebih banyak pekerjaan. Menurut Simanjuntak (2001), Jika seorang pekerja mengurangi porsi waktu luang dan menggantinya dengan waktu untuk melakukan pekerjaan, maka orang tersebut cenderung memperoleh pendapatan yang lebih baik. Hal ini juga sesuai dengan penelitian yang telah dilakukan Hanum (2017) dan Febriyanto (2019) yang menyatakan bahwa banyaknya curahan jam kerja berpengaruh positif pada pendapatan pekerja. 


\section{KESIMPULAN}

Berdasarkan hasil dan pembahasan, kesimpulan yang diperoleh adalah evaluasi model menunjukkan bahwa SMOTE dapat digunakan untuk mengatasi salah klasifikasi pada kategori minor data tidak seimbang dalam regresi logistik biner. Untuk variabel yang secara signifikan mempengaruhi tingkat pendapatan pekerja nformal di Provinsi Daerah istimewa Yogyakarta yaitu jenis kelamin, pelatihan kerja, tingkat pendidikan, lapangan usaha, umur, lama usaha, dan jam kerja. Kecenderungan pekerja informal berjenis kelamin lak-laki, pernah mengikut pelatihan kerja, berpendidikan tinggi, bekerja pada sektor sekunder, berusia kurang dari 60 tahun, dan lebih banyak jam kerja; lebih besar untuk memiliki pendapatan tinggi.

\section{DAFTAR PUSTAKA}

Agresti, A. (2000). Categorical Data Analysis. 2nd edition. New Yok: John Wiley \& Sons.

Arfida, BR. (2003). Ekonomi Sumber Daya Manusia. Jakarta: Ghalia Indonesia.

Badan Pusat Statistik. (2019). Keadaan Angkatan Kerja Daerah Istimewa Yogyakarta Tahun 2019. D.I Yogyakarta : BPS.

Badan Pusat Statistik. (2019). Pedoman Pencacah Survei Angkatan Kerja Nasional (SAKERNAS) Semesteran 2019. Jakarta : BPS.

Badan Pusat Statistik. (2019). Statistik Kesejahteraan Provinsi Daerah Istimewa Yogyakarta Tahun 2019. D.I Yogyakarta : BPS.

Badan Pusat Statistik. (2020). Statistik Ketenagakerjaan Provinsi Daerah Istimewa Yogyakarta Tahun 20192020. D.I Yogyakarta : BPS.

Becker, Gary Stanley. (1993). Human Capital : A Theoretical And Empirical Analysis, With Special Reference To Education 3rd Edition. London : The University of Chicago Press, Ltd.

Bhaskara, A.A. Yoga,et al.. 2019. Pengaruh Pendidikan, Jenis Kelamin, Dan Status Pekerjaan Terhadap Pendapatan Pekerja Di Bali. E-Jurnal Ekonomi Pembangunan Universitas Udayana, Vol.8.No.9 September 2019.

Chawla, Nitesh V., et al.. 2002. SMOTE: synthetic minority over-sampling technique. Journal of Artificial Intelligence Research (JAIR), 16, 321-357. https://doi.org/10.1613/jair.953

David W.. Hosmer, Lemeshow, S., \& Rodney X.. Sturdivant. (2000). Applied logistic regression. New York: Wiley.

Faridi, M.Z, et al.. 2013. Earning Determinants and Urban Informal Sector: Evidence from District Multan. Journal of Pakistan Association of Dermatologists 14(2):132-148.

Febriyanto, Aditya. 2019. Analisis Faktor-Faktor Yang Mempengaruhi Pendapatan Pelaku Usaha Sektor Informal (Studi Kasus Di Objek Wisata Pantai Balekambang, Kabupaten Malang). Jurnal Ilmiah FEB UB Vol.8, No.1.

Hanum, N. 2017. Analisis Faktor-faktor Yang Mempengaruhi Pendapatan Pedagang Kaki Lima di Kota Kuala Simpang. Jurnal Samudra Ekonomika, 1(1), 72-86,

Jian, C., Gao, J., \& Ao, Y. (2016). A New Sampling Method for Classifying Imbalanced Data Based on Support Vector Machine Ensemble. Journal Neurocomputing. 193, 115-122, https://doi.org/10.1016/j.neucom.2016.02.006

Karsmakers, P., Pelckmans, K., \& Suykens, J. a. K. (2007). Multiclass kernel logistic regression: a fixed-size implementation. 2007 International Joint Conference on Neural Networks. doi: 10.1109/IJCNN.2007.4371223.

Pasay, N.H.A. \& Indrayanti, R. (2012). Pengangguran, Lama Mencari Kerja, dan Reservation Wage Tenaga Kerja Terdidik. Jurnal Ekonomi dan Pembangunan Indonesia. 12(2): 116-135.

Putri, AD \& Setiawina, D. 2013. Pengaruh Umur, Pendidikan, Pekerjaan Terhadap Pendapatan Rumah Tangga Miskin Di Desa Bebandem. E-Jurnal Ekonomi Pembangunan Unud : 173-180.

Sukirno, Sadono. 2008. Mikroekonomi: Teori Pengantar. Edisi Ketiga. Jakarta: PT. Raja Grafindo Persada.

Simanjuntak, P.J. 2001.Pengantar Ekonomi Sumber daya Manusia Edisi Kedua. Jakarta : Lembaga Penerbit Fakultas Ekonomi Universitas Indonesia.

Siringoringo, Rimbun. (2018). Klasifikasi Data Tidak Seimbang Menggunakan Algoritma SMOTE Dan KNearest Neighbor. Jurnal ISD Vol.3 No.1 Januari -Juni 2018.

Untoro, Meida Cahyo dan Joko Lianto Buliali. (2018). Penanganan imbalance class data laboratorium kesehatan dengan Majority Weighted Minority Oversampling Technique. Jurnal Ilmiah Teknologi Sistem Informasi 4 (1), 2018 : 23-29. 
Yanminsun, Wong, Andrew \& Kamel, Mohamed S.. (2011). Classification of imbalanced data: a review. International Journal of Pattern Recognition and Artificial Intelligence. 23. $10.1142 / \mathrm{S} 0218001409007326$. 